\title{
Article
}

\section{The Role of Regulators in Promoting the Procurement of Flexibility Services within the Electricity Distribution System: A Survey of Seven Leading Countries}

\author{
Karim L. Anaya * and Michael G. Pollitt \\ Energy Policy Research Group, Cambridge Judge Business School, Cambridge CB2 1AG, UK; \\ m.pollitt@jbs.cam.ac.uk \\ * Correspondence: k.anaya@jbs.cam.ac.uk
}

Citation: Anaya, K.L.; Pollitt, M.G The Role of Regulators in Promoting the Procurement of Flexibility Services within the Electricity Distribution System: A Survey of Seven Leading Countries. Energies 2021, 14, 4073. https://doi.org/ $10.3390 /$ en14144073

Academic Editor: Vincenzo Bianco

Received: 7 June 2021

Accepted: 30 June 2021

Published: 6 July 2021

Publisher's Note: MDPI stays neutral with regard to jurisdictional claims in published maps and institutional affiliations.

Copyright: (c) 2021 by the authors. Licensee MDPI, Basel, Switzerland. This article is an open access article distributed under the terms and conditions of the Creative Commons Attribution (CC BY) license (https:// creativecommons.org/licenses/by/ $4.0 /)$.
Abstract: This paper identifies and explores regulatory issues that may have an impact on the use of flexibility services by distribution utilities to solve grid constraints. This can be done by flexible distributed energy resources which can be instructed, for instance, to reduce export generating capacity or increasing consumption. We want to identify how regulation can better support the development of the future distribution utility in its role as neutral market facilitator, enabling more competition in local flexibility markets and optimal use of resources. A set of questionnaires were designed to capture the insights around important aspects of the regulation of flexibility markets (utilities' network incentives, network tariff structure, market design for flexibility markets, etc.). These were sent to distribution utilities, energy regulators, energy marketplaces, energy associations and relevant experts from seven jurisdictions. The responses suggest a collective interest in the procurement of flexibility services by distribution utilities from distributed energy resources. New regulations, the adaptation of current rules and recent consultations reflect this. However, the amount of progress with and preferences for key regulatory changes differ across jurisdictions.

Keywords: distribution system operators; flexibility services; regulation; procurement; distribution energy resources

\section{Introduction}

The trend towards higher shares of intermittent renewable electricity within the electricity system is manifest across many jurisdictions. Much of this new generation is connected to lower voltage electricity distribution networks rather than to the high voltage transmission system. This creates the need to manage the fluctuations that these generators create on the local distribution system so that network capacity constraints are not violated, and power quality requirements are met. New electrical loads such as electric vehicles and heat pumps also pose potential challenges for grid management. Distribution system operators need to be adapted to these challenges [1]. Overall, this energy transition is increasing the demand for 'flexibility' within the electricity distribution system where generators, loads and new players (such as commercial batteries) are incentivized to respond to network condition. These potential sources of flexibility within the distribution system are known as 'distributed energy resources' or DER.

There are different ways that countries promote flexible electricity resources via markets, tariffs, connections arrangements (access rights), etc. Indeed, energy regulatory agencies in the European single market are required to provide incentives to distribution system operators (DSOs) to procure flexibility services and standardised market products at national level.

In Europe, the EU Clean Energy Package (CEP) [2] specifies directions of travel regarding the need for the use of more market-based approaches for procuring flexibility services, smart meters, data management, more active networks, etc. It also states that 
the distribution system operator (DSO) should be remunerated for the procurement of flexibility services to allow to recover reasonable IT and infrastructure costs.

The existing literature related to flexibility markets is extensive in relation to market design for electricity at distribution and transmission, market clearing methods, optimization methods, role of aggregators, peer-to-peer, etc. For a brief discussion of these studies see Section 1 of our previous paper in this Special Issue [3]. The literature about the role of regulation in promoting the use of more flexibility, especially at distribution, needs further expansion. This paper innovates in providing key insights from key energy parties about the role of regulation in the transition to more active distribution utilities.

The aim of this paper is to identify and explore regulatory issues that may have an impact on the use of flexibility solutions (with a focus on those provided by DER) by distribution utilities. In line with our previous paper in this Special Issue the same jurisdictions have been selected (Australia, France, Germany, Great Britain, Japan, The Netherlands, Norway). A set of questionnaires have been designed to capture key insights for each of these aspects from participants, including distribution utilities, energy regulators, energy marketplace and experts (18 in total). We explore twelve regulatory issues raised by emerging innovative solutions to the rising flexibility requirements. These issues are briefly discussed in Section 2. This paper is based on a report that the authors performed under the context of the MERLIN innovation project in Great Britain [4].

The structure of the paper is as follows. Section 2 provides some background on different regulatory aspects that need to be taken into consideration in the adoption of flexibility solutions by distribution utilities. Section 3 explains the methodology. Section 4 compiles and discusses the responses given by all the participants on each regulatory aspect in turn and identifies lessons learned. Section 5 concludes.

\section{How Regulators Promote Flexibility}

In this section we identify a number of ways in which regulators could promote the procurement of flexibility and investigate the extent to which the jurisdictions that we look at have already, are in the process of, or should in the future use each of these ways to promote flexibility. Many of these topics were initially identified in our previous paper on the same Use Cases [5] and complemented by an additional literature review [6-11]. The ways this could be done are highlighted in the following paragraphs. The characteristics of the jurisdictions we look at are noted in Table 1.

Table 1. Distribution market in the seven jurisdictions.

\begin{tabular}{|c|c|c|c|c|c|c|c|}
\hline \multirow[b]{2}{*}{ Country } & \multicolumn{3}{|c|}{ National Figures (Distribution) } & \multicolumn{4}{|c|}{ Largest Distribution Utility } \\
\hline & $\begin{array}{l}\text { Number of } \\
\text { DSOs }\end{array}$ & $\begin{array}{l}\text { Customers } \\
\text { (Million) }\end{array}$ & $\begin{array}{l}\text { Network Length } \\
\text { (Million km) }\end{array}$ & Name (4) & $\begin{array}{l}\text { Customers } \\
\text { (Million) }\end{array}$ & $\begin{array}{c}\text { Customers } \\
\text { Density } \\
\text { (\#cust./km) }\end{array}$ & $\begin{array}{c}\text { Market Share } \\
\text { (Customers) }\end{array}$ \\
\hline Australia (1) & 15 & 10.45 & 0.75 & Ausgrid & 1.8 & 41.7 & $16.7 \%$ \\
\hline France (2) & 148 & 36.9 & 1.4 & Enedis & 36.0 & 26.5 & $97.6 \%$ \\
\hline Germany (3) & 883 & 51.4 & 1.8 & Innogy (E.oN) & 6.7 & 19.2 & $13.1 \%$ \\
\hline Great Britain & 14 & 29.8 & 0.85 & UKPN & 8.3 & 44.0 & $27.9 \%$ \\
\hline Japan & 10 & 70.4 & 0.99 & Tepсо & 25.5 & 70.7 & $36.2 \%$ \\
\hline the Netherlands & 7 & 8.3 & 0.26 & Liander & 3.2 & 35.2 & $38.6 \%$ \\
\hline Norway (5) & 120 & 3.1 & 0.33 & Elvia & 0.9 & & $29.0 \%$ \\
\hline
\end{tabular}

(1) In Australia, the total number of customers and network length exclude the ones from Western Australia region; (2) In France, the number of DSOs includes (1) DSO and (147) local distribution utilities-ELD); (3) In Germany, E.oN took over Innogy Group in September 2019; (4) Ausgrid, Enedis, UKPN and Tepco are involved in this study; (5) In Norway, Elvia was created as a result of merging Eidsiva Nett AS and Hafslund Nett AS in January 2020. Source: [12-24], utilities' websites.

The way in which network operators are regulated may influence distribution utilities' preferences between the use of traditional solutions (i.e., reinforcement), flexible solutions or a combination of the two [25]. In all the jurisdictions that are part of this study, except for Japan, incentive regulation is the mechanism used to regulate distribution networks 
(via a revenue or price cap), with different levels of sophistication across jurisdictions. The totex approach (which provides the freedom to select either opex or capex to meet network demands) looks superior to non-totex approaches which may bias network expenditure towards capex or opex based solutions. One of the things we want to know is whether the current regulatory mechanism (including ongoing or future proposals), can incorporate the value of flexibility in the regulatory revenue or price formula.

The use of flexibility services by distribution utilities may also be encouraged by a more cost reflective tariff structure, such as tariffs for the use of the networks and connection charges. The use of standardized definitions of flexibility products or services may also help to promote flexibility services. This facilitates the development of deeper markets with more participants.

Regulators can also play an important role in specifying the market design for flexibility markets. Appropriate market designs can help to capture the value that decentralized resources such as DER can provide to the electricity system [26]. The role of the distribution utility as a neutral market facilitator is a possibility that is envisaged in the future. In fact, jurisdictions are already experimenting with this approach to evaluate the viability and any potential regulatory intervention. Facilitating flexibility trading between third parties where the distribution utility may act as an intermediary is an example of being a neutral market facilitator. The role of DSOs in facilitating peer-to-peer (P2P) flexibility trading is also something we explore.

Smart meters are key enablers of unlocking flexibility resources within the distribution system. Regulators may need to change the rules framework for smart meters to fully exploit the potential of flexibility arising from the existence and use of smart meters. Another related issue for regulators is rules on participation of aggregators in flexibility markets. This has the advantage of unlocking small DERs, but the disadvantage of breaking the link between physical ownership and operation and market participation and allowing 'virtual' market participation.

Managing and procuring flexibility to solve network constraints, congestion, etc., requires more active networks and more coordination between network operators (i.e., distribution utilities and transmission system operators). Better coordination is required among parties for a more cost-efficient, sustainable and reliable system operation [27], which leads to lower costs for users of the electricity grid. This coordination can be encouraged via regulation [28]. An important part of this coordination can be allowing DSOs to procure flexibility on behalf of transmission system operators (TSOs). We want to know how jurisdictions are progressing in this field and the instruments (if any) they are using to enhance coordination between DSOs and TSOs.

Feed-in Tariffs (FiTs) for smaller generators are a potential source of inflexibility within the distribution system because generators are paid a fixed price regardless of market or system conditions. Changes to FiT regulation can facilitate greater participation of DER in flexibility markets.

Access and management of customer data (including DER customers) is critical to capture and maximise the value of flexibility across all parties (e.g., network operators, customers, retailers/suppliers, aggregators). The integration of DER creates opportunities but also challenges. Technological advances can help to have more automated systems to control and monitor data, but regulatory intervention may still be needed to set standards of best practice. Data needs to be interoperable, accurate, accessible, and regulation can help with this.

Finally, the creation of a standard social cost benefit methodology for the evaluation of flexibility services can promote the appropriate procurement of flexibility. Indeed, one might expect the absence of a regulator approved methodology is likely to lead to unsustainable inconsistencies in flexibility procurement between DSOs in a single jurisdiction. 


\section{Methodology}

In order to capture key insights about the way in which regulatory frameworks (associated with each of the topics highlighted in the previous section) can facilitate and encourage the use of flexibility by network operators, two similar questionnaires were designed and sent to representatives of the seven jurisdictions, see Appendix A. In these jurisdictions, there are some indication of supportive regulatory frameworks for the use of flexibility services by network operators and information about recent innovative projects/initiatives and trials that favor the use of flexibility services to solve network constraints.

Questionnaire 1 looks at the regulatory framework that supports the use of flexibility services from a general perspective. This questionnaire was sent to regulatory energy authorities, energy associations and relevant experts. Questionnaire 2 looks at the regulatory framework too but with a focus on the Use Cases evaluated in our previous paper in this Special Issue. This questionnaire was sent to the parties involved in these initiatives such as distribution utilities and marketplace platforms. The two questionnaires can be found in Appendix B.

The questionnaires aim to capture for each regulatory topic what has been already changed (past), and what is currently under consideration (present) and what should be changed (future). In some cases "changes currently in consideration" or those that "should be changed" may also refer to things that have already been reported as changed. In addition, considering that not all the changes have the same importance or priority, we provide the opportunity to identify the top 3 . We think that the diversity of parties and the mix of experiences provide a more comprehensive indication about the role of regulation associated with the deployment of flexibility markets in each jurisdiction from different business perspectives.

We have received a total of 18 questionnaires (out of 23 sent) over the period June to July 2020. We have at least one key organization per each jurisdiction (i.e., the regulatory authority or the largest distribution utility) with a maximum of 7 representatives per jurisdiction.

The questionnaire is not a representative survey given the small number of highly specialized individuals who know about these topics. In the existing literature, we can find surveys that involve energy related topics such as willingness to pay for renewable energy, energy saving technologies, renewable microgeneration, with diverse methods such as factor analysis, econometrics, etc. [29-31], but not related to flexibility services and market design which is still a work in progress even in most advanced economies.

What we are trying to get at with the questionnaires is a general impression of the issues in particular jurisdictions provided by informed participants. The following steps were followed.

- $\quad$ First, we summarise our overall impression per each regulatory topic (12 in total, identified in [4]), such as the number of jurisdictions and respondents that acknowledge changes or potential changes to the associated topic and the most relevant ones for them (top 3 only).

- $\quad$ Second, we use a country-level summary table per each topic (placed at the start of each subsection) to give an overview of the respective responses. If at least one of the participants confirmed: (1) any existing change, or (2) changes being considered or changes that should be considered, we mark the country response as a "Yes".

- $\quad$ Third, we discuss specific differences between respondents (per each country) in the text that follows. We also support the responses and discussion in each subsection, with additional literature review and references from their respective national regulatory agencies, distribution utilities and other organisations.

Unsurprisingly, there is a lot nuance between individual participants in the survey who work for different organisations. However, there is also a lot of agreement, given that at the national level many of the individuals know each other and interact in the same industry fora. 


\section{Survey Findings}

This section summarises the responses provided by the 18 participants from the 7 jurisdictions involved in this study and identifies main findings. Table 2 summarises the responses per type of participant.

Table 2. Summary of participants per country.

\begin{tabular}{lcccccccc}
\hline Summary of Responses & AU & FR & DE & GB & JP & NL & NO & Total \\
\hline Regulator & 1 & & 1 & 1 & & 1 & 1 & 5 \\
\hline Distribution utilities & 1 & 1 & 1 & 3 & 1 & & & 7 \\
\hline Energy Associations & 1 & & & 1 & & & & 2 \\
\hline Platforms/marketplaces & & & & 2 & & & 1 & 3 \\
\hline Experts & & & & & 1 & & & 1 \\
\hline number of responses & 3 & 1 & 2 & 7 & 2 & 1 & 2 & 18 \\
\hline
\end{tabular}

\subsection{Changes to Utilities' Revenue Incentives}

Respondents from three jurisdictions acknowledge changes to the utilities' revenue incentives that may favor the use of flexibility. Respondents from 5 jurisdictions (a total of 10 out of 18 responses) have indicated current or future changes to the utilities 'revenue incentives that facilitate the use of flexibility. Change to utilities revenue incentives ranks first in the identification of top 3 issues by the respondents ( 8 out of 18 ) in four jurisdictions (see Table 3).

Table 3. Changes to utilities' revenue incentives-response summary.

\begin{tabular}{|c|c|c|c|c|c|c|c|}
\hline Utilities' Revenue Incentives & AU & FR & $\mathrm{DE}$ & GB & $\mathbf{J P}$ & NL & NO \\
\hline already changed? & yes & & & yes & yes & & \\
\hline $\begin{array}{l}\text { change being considered or should } \\
\text { be considered? }\end{array}$ & yes & yes & yes & yes & & yes & \\
\hline top 3 & yes & & yes & yes & yes & & \\
\hline
\end{tabular}

In Japan, one of the respondents mentions a recent change in the price control methodology, moving from rate of return (cost-of-service regulation) to incentive regulation (revenue cap), to be implemented in 2023.

In The Netherlands, the respondent remarks that there are no specific incentives to promote the procurement of flexibility, but the regulatory scheme adopted (yardstick competition based on totex) gives the opportunity for distribution utilities to select the most efficient mix of expenses: opex (i.e., procuring flexibility) and capex (i.e., conventional grid reinforcement). It was suggested that the distribution utilities may get limited additional revenues that are relatively small in comparison to the incurred operational costs. The size of the revenue is equal to the incremental capacity made available through congestion management times the regulated tariff. On top of this, it may be the case that those DSOs that spend more on capex (i.e., timely investment in network reinforcement) perform better in comparison to the benchmark and those that procure flexibility to manage congestion with relatively high opex performing worse. This is something that is currently under evaluation by the regulator.

In Germany, one of the respondents points out an ongoing discussion on efficiency incentives for congestion management. For instance, based on the current regulatory framework, distribution utilities are allowed to compensate controllable loads or feedin generation (generators are entitled to $95 \%$ of the missed revenue capped to $1 \%$ of revenue of total power production) in the case of network constraints (i.e., by controlling their loads or via curtailment, respectively), further details are provided in Section 4.2. 
Compensation costs (i.e., feed-in generation) are classified as permanently "non controllable cost" and therefore are not included in efficiency benchmarking. On the other hand, market-related measures are allocable as operating costs and included in the efficiency benchmarking. There are no incentives for distribution utilities to look for more efficient solutions (i.e., flexibility via a market-based approach) [32]. Another respondent suggests that the obligation that DSOs have in connecting 100\% of generators that produce electricity from renewable sources (under the Renewable Act-EEG), makes it impossible to foresee the need for connection capacity building on the use of flexibility. The EEG gives generators of electricity from renewable resources priority in grid connection and in dispatch order (see $\S 8$ and $\S 11$ from EEG).

In Australia, one respondent points to a scheme to support distribution utilities to find non-network options with a focus on demand management, up to around \$1billion over five years: the demand management incentive scheme and innovation allowance. The first one has three features: cost uplift (size of the incentive cap to $50 \%$ of expected costs), net benefit constraint (incentive cannot be higher than project's expected net benefits) and overall incentive constraint (total incentive cannot exceed $1 \%$ of the distribution business allowed revenue for the same year). The second one is a demand management $R \& D$ fund [33].

In GB, many of the respondents agree that a change has already been made with the introduction of a totex regulatory model in RIIO ED1 price control in 2015. The RIIO (Revenue = Incentives + Innovation + Outputs) framework is applied to electricity and gas networks. One respondent points out that the totex regulatory model is critical and is evolving with some key changes for the next five- year regulatory period (RIIO ED2) starting in April 2023. One of lessons learned from the current price control is that overall costs to consumers have been too high. Among the drivers of this is underspend against allowances and rewards from quality incentives (i.e., Interruptions Incentive SchemeIIS), [34]. Some of the key changes are: (1) the introduction of a Net Zero re-opener in response to Net Zero GHG emissions targets set in the UK by 2050 allowing the price control to be adaptable; (2) a set of obligations, incentives and deliverables; (3) strategic investment models; (4) an innovation fund (SIF) that will replace the RIIO-1 network innovation competition (NIC); (5) enabling whole system solutions; and (6) the introduction of a CAM (Coordinated Adjustment Mechanism) re-opener [35]. It was mentioned that procuring flexibility can save totex (e.g., by reinforcement avoidance or deferral expenditure) but also means lower regulatory asset value (RAV) and that more incentives to manage uncertainty (i.e., load growth) via flexibility are needed. It is also suggested that these should be part of totex. Another respondent suggests the consideration of linking flexibility with outputs and with the benefits that this can bring to the whole system. A third remarks that no-additional change is required to the current scheme for the procurement of flexibility services: there are sufficient incentives for distribution utilities. One of the marketplace respondents indicates the need to incorporate flexibility within the distribution companies' (DNOs') business model and incentives to use it rather than BAU approaches (i.e., traditional reinforcement).

Many of the jurisdictions use revenue cap regulation based on totex, which gives more freedom to the distribution utility to select the best combination of costs (operational and capital). What we observe is that even though these models are considered superior, distribution utilities are not necessarily encouraged to use flexibility as an alternative option (even if it can be the most cost-efficient solution). The way these costs are recovered plays an important role in this. If these costs are categorized as non-controllable costs, then they cannot be part of a benchmark and hence there is no incentive to reduce them via competitive procurement. Even if totex is benchmarked flexibility solutions may be discouraged due to exposure to cost penalties (e.g., in the Netherlands). Regulation should promote the use of flexibility when it is the most cost-efficient option. The number of participants that acknowledge ongoing changes or future changes shows that some improvements to the current models are still required. 


\subsection{Changes to Network Tariff Structure}

Changes to network tariff structure have been reported in two jurisdictions only. Even though, in most jurisdictions (6 out of 7) changes to network tariff structure are being considered or should be considered according to the respondents (15 out of 18). Network tariff structure is among the 3 top regulatory changes according to respondents $(7$ out of 18), and the one with the highest level of consensus across the seven jurisdictions (5 out of 7). Table 4 summarises the responses.

Table 4. Changes to network tariff structure-response summary.

\begin{tabular}{cccccccc}
\hline Network Tariff Structure & AU & FR & DE & GB & JP & NL & NO \\
\hline $\begin{array}{c}\text { already changed? } \\
\begin{array}{c}\text { change being considered or should } \\
\text { be considered? }\end{array}\end{array}$ yes & yes & yes & yes & & yes & yes \\
\hline top 3 & yes & yes & & yes & & yes & yes \\
\hline
\end{tabular}

In Norway, a proposal to modify the current network tariff structure to low voltage (LV) customers (e.g., households, vacation homes, smaller commercial business) has been made [35]. A new capacity-based tariff design (currently mainly volumetric without incentives to reduce capacity) to LV customers has been proposed. At present only a few DSOs have already implemented capacity tariffs. It is important to note that the proposal for a new tariff design does not change the revenue cap model used by NVE to regulate the DSOs (yearly income cap). The determination of tariffs should be within their income cap. Three models of potential tariff design are recommended, in all of them the energy charge is equivalent to the marginal cost of network losses (only if capacity is not constrained). DSOs may adopt one of them or a combination of them. If the DSOs face capacity constraints, the energy charge may reflect this in the form of a price signal (e.g., via time-of-use differentiation), which may involve dynamic or static pricing [36]. However, the proposal does not specify whether this price should be included, or how it can be regulated. According to the proposal, a short-term capacity constraint flexibility can be an option (i.e., via a market-based approach), where the price is defined by the market instead. Nevertheless, it is suggested that the introduction of this price signal may add more complexity to the tariff design. Another respondent has suggested the need to have tariff structures aligned with the development of flexibility markets. In the case of a constraint, flexibility assets that operate at a specific time of the day can be penalized, then market signals should be used instead.

In The Netherlands, according to one respondent the limitations of the current tariff design have been explored in terms of: (1) the use of a uniform capacity-based tariff for residential consumers introduced in 2009 [37]; (2) the lack of level a playing field in the flexibility market between both consumption and injection; (3) penalties applied to larger consumers when consumption is increased; and (4) non-existent locational signals in distribution tariffs. Another barrier that has been acknowledged is the consideration of a maximum producer tariff set at $€ 0.50$ per MWh (generators). According to the respondent, the introduction of tariffs for producers would make the current network tariff more robust. The introduction of more flexible tariffs (i.e., dynamic pricing) has been assessed in a recent study [38]. The results suggest that the time is not yet right to implement dynamic pricing. Among the reasons are the conflict with the current tariff scheme (based on static rates for each tariff category that are the same through the year regardless of location), the higher administrative burden and the need for more complex regulation. If dynamic pricing did exist, the purchase of flexibility (services) via a competitive mechanism would be preferred instead.

In Germany, one of the respondents points out that changes regarding the connection and control of electric vehicles and heat pumps are being considered. In line with the current regulatory framework (Section 14a Energy Industry Act-EnWG), suppliers and 
end consumers are entitled to a discount in the distribution network tariff in exchange for transferring the control of the customer's devices connected at LV (i.e., controllable loads) to adjust their consumption in case of network constraints. However, the size of the discount is not regulated and varies considerably across distribution utilities (c. 883 DSOs) with an average reduction of $55 \%$ equivalent to $3.44 \mathrm{ct} / \mathrm{kWh}$ (with the lowest and highest discount of $6 \%$ and $91 \%$, respectively) [14]. Distribution utilities are required to meet this obligation, even though there may be no benefit to them. Defined network segments above a specific capacity could help [28]. Then, what is still missing is the framework for the reduction in network charges and contractual arrangements (i.e., control actions reserved by distribution utilities and those by suppliers). Section 14a of the EnWG is currently under revision. Different options for controlling flexible loads are being evaluated including the establishment of a few hours a day for controlling the loads in case of constraints and differentiation in network access (i.e., conditional and unconditional access with thresholds).

In Australia, one respondent notes recent network access and tariff reforms proposed/actioned by a distribution utility (South Australian Power Distribution) and already approved by the regulator. The aim of these reforms is to manage minimum demand in the midday due to excess solar generation. A new tariff scheme based on time in use will be applied from 1 July 2021. The scheme proposes a "solar sponge" structure with the lowest off-peak rates at midday, for details see [39]. A modification of the export limit scheme (currently static and set at $5 \mathrm{~kW}$ ) is also acknowledged. Households with rooftop capacity will have the opportunity in 2021 (targeted) to choose between static or dynamic export limits (to be set based on real-time network conditions). The dynamic scheme offers a higher export limit to customers, but export restrictions (i.e., curtailment) will be applied by the distribution utility (occasionally) in order to remain within network capacity limits (especially when grid voltage rises). Customers will export solar energy around 97\% of the time. Other respondents agree that adequate network tariff structure contributes to a more equitable approach. This can be in the form of more locational pricing, local settlement rules and allowing pricing on exports to the grid. A recent policy consultation [40], proposes three rule change requests that aim to facilitate the efficient integration of DER for the grid of the future [41]. These changes require the provision of the right incentives to distribution utilities to provide export services to DER and the establishment of the correct export charges. An amendment of the National Electricity Rules (NER) which mandates the economic regulation of distribution utilities in the National Electricity Market (NEM) may be required. Currently NEM regulation (clause 6.4) does not allow distribution utilities to charge use of system charges for export services (costs recovered via connection charges and consumption charges). Considering that the service classification sets the type of economic regulation (i.e., distribution services currently linked to consumption), it is important to clarify and to re-define the definition/scope of distribution services.

In France, it was acknowledged by the respondent that flexibility and network tariffs are two different and complementary ways to increase investment options, help grid optimization and to prevent constraints. It is an ongoing discussion with the energy regulator to include the cost of procuring flexibility in the distribution tariff for the next regulatory period (Turpe 6). A closer look at recent regulator (CRE) consultations [42] shows the consideration of dynamic pricing to make recommendations related to the implementation of dynamic pricing as suggested in European Directive 2019/944.

In Great Britain, one of the respondents points out an ongoing reform of network access and charges (Electricity Network Access and Forward-Looking Charging Significant Code Review-SCR) launched in December 2018. This evaluation covers four policy areas (access rights for transmission and distribution, distribution charges (DUoS), distribution connection charging boundary and transmission charges (TNUoS)). Shortlisted options were identified [43]: in terms of access rights (e.g., improved options for non-firm connections, tradable access within same local area), distribution connection charging boundary (e.g., move to a shallow(er) approach, alternative payments), distribution charges (e.g., use 
of forecast of incremental reinforcement needed at extra HV, consideration of an ultra-long run cost model, the introduction of more granular zones for charging and time bands for time of use charges) and transmission charges (e.g., change to reference node, consideration of time of use bands and/or agreed capacity rights). A closer look at the relevant documentation suggests that access right reforms (definition and choices) are focused on larger users, dynamic charges for both transmission and distribution are not an option now, and that non- available/inaccurate network data is behind the exclusion of some potential reforms. Another respondent expresses concerns about whether more granularity and dynamic network tariffs will be beneficial, suggesting that it can be low at lower voltages. A different respondent suggests that the procurement of flexibility (i.e., via markets) by distribution utilities should be limited to being used against load related reinforcement for demand in line with the current charging boundary.

Comprehensive reform of both transmission and network charges to be more dynamic in time and space is something that is on the agenda of several jurisdictions, but all the jurisdictions that we have looked at are proceeding cautiously on this. Full dynamic nodal pricing, at every conceivable node where DER flexibility might make a difference is some way off. However, there have been some interesting developments to better reflect costs particularly for solar export, which is becoming significant in some jurisdictions. There seems little doubt that creative (i.e., targeted) use of price signals delivered via network charges can encourage DER flexibility.

\subsection{Changes to Definition of Products/Service and Standardization}

Only in a few jurisdictions is it acknowledged that a change in the definition of products/services and standardization facilitates the procurement of flexibility. However, respondents from four jurisdictions report current changes under consideration or agree that changes should be considered ( 8 out of 18). This has been placed as one of the top 3 by two respondents only (see Table 5).

Table 5. Changes to definition of products/services and standardization—response summary.

\begin{tabular}{|c|c|c|c|c|c|c|c|}
\hline $\begin{array}{c}\text { Definition of Products/Services } \\
\text { and Standardisation }\end{array}$ & AU & FR & $\mathrm{DE}$ & GB & JP & NL & NO \\
\hline already changed? & yes & & & yes & & & \\
\hline $\begin{array}{c}\text { change being considered or should } \\
\text { be considered? }\end{array}$ & yes & & yes & yes & & yes & \\
\hline top 3 & & & & yes & & yes & \\
\hline
\end{tabular}

In GB, different respondents confirm the existence of a standard set of flexibility products for distribution utilities [44]. In light of this, another respondent points out that changes to licenses are being made in coordination with the system operator and other stakeholders. A third respondent notes the need for a "technology agnostic" product and for product standardisation when considering an increase in the number of interfaces and platforms. Standardised and adaptive products are also recommended for the procurement of flexibility by the GB regulator [45].

In The Netherlands, the respondent suggests the introduction of two products as a result of the adaptation of network codes to improve rules on congestion management by distribution utilities: (1) a capacity constraint product and (2) a redispatch product; to be used before and after closing the day-ahead market, respectively.

In Norway, one of the respondents points to ongoing trials that aim to evaluate new products, bid size, etc. (e.g., a pilot for $1 \mathrm{MW}$ balancing bids and a pilot for fast frequency reserves).

A lot of attention has been given to product standardization already across our jurisdictions. However, there is some concern that instead of specifying the product, the underlying characteristics should be specified as it is these that consumers value and that 
this would allow the trading of products of different qualities provided by very different DER. This is in line with the recommendation of [46] on the rationalization of frequency response markets, where the time to respond should be valued explicitly in the evaluation of bids process rather than narrowly be part of the product definition.

\subsection{Specification of Market Design Rules for Local Flexibility Markets}

Except for one jurisdiction (The Netherlands), the market design for local flexibility markets has not been settled. However, many of the respondents agree that changes are being considered or should be considered (in 5 out of 7 jurisdictions). Like the previous two changes, market design rules for local flexibility markets are among the top three changes selected by the respondents (see Table 6).

Table 6. Specification of market design rules for local flexibility markets—response summary.

\begin{tabular}{|c|c|c|c|c|c|c|c|}
\hline $\begin{array}{l}\text { Market Design for Local } \\
\text { Flexibility Markets }\end{array}$ & AU & FR & DE & GB & $\mathrm{JP}$ & NL & NO \\
\hline already changed? & & & & & & yes & \\
\hline $\begin{array}{l}\text { change being considered or should } \\
\text { be considered? }\end{array}$ & yes & & yes & yes & yes & Yes & \\
\hline top 3 & yes & & yes & yes & yes & & \\
\hline
\end{tabular}

In The Netherlands, one of the respondents mentions key developments that relate to flexibility markets such as the development of a platform for local congestion management (Grid Operators Platform for Congestion Solutions-GOPACS [47], one of the Use Case discussed in our first paper in this Special Issue). This makes use of ETPA (a market energy platform) for clearing the market, for details see [5].

In Japan, one respondent suggests that there is no official plan to create local flexibility markets, but a review of the international experience is being undertaken in the expert meeting on the Platform for Distributed Energy Systems [48]. They also mentioned the funding support from government (Ministry of Economy, Trade and Industry-METI) for demonstrators (e.g., VPP, P2P). Another suggests that some progress is noticeable and points to the creation of the Expert Committee for flexibility markets also known as "SupplyDemand Adjustment Market", with the aim of discussing a potential market design (e.g., flexibility menus, bidding methods).

In Norway, one respondent acknowledges the establishment of a framework for pilot and demonstration projects [49], with two main purposes: "to provide better information about regulations and make the application process if necessary for dispensation later". Five dispensations have been identified to date. The need for trials before implementing permanent regulatory changes has been acknowledged. A different respondent states that the development of flexibility markets is in its infancy and there is a need for additional exploration to see how flexibility markets can and should develop.

In Germany, one respondent agrees that if the distribution utility maintains strict unbundling, the creation of dedicated markets for regional flexibility at the DSO level is needed.

In France, the respondent suggests the need for experiments to define an appropriate market design. There is a current call for tenders (trials) to procure local flexibility resources [50].

In Australia, one of the respondents suggests that the Post-2025 Market Design for the Electricity Market (NEM) - a long term fit for purpose market framework-will significantly change the way in which distribution and transmission networks business will operate. In fact, this may have an important effect on the way in which local flexibility markets will operate in Australia. For instance, as part of this initiative the Energy Security Board (ESB) is working on a two-sided market project [51]. In a two-sided market all participants (sellers and buyers) respond to price based on their true cost preference (i.e., 
currently in the wholesale market demand is taken as "given" and based on forecasts). A two-sided market would facilitate the role of the distribution utility (DNSP) as DSO in terms of network optimisation considering DER operation and identifying constraints and the need for services to alleviate them.

Another respondent from Australia mentions the work that the Open Energy Networks Project (OpEN) which aims to look for market scenarios to integrate DER into local distribution networks. Four scenarios have been evaluated here: (1) single integrated platforms, (2) two-step tiered platform (TST), (3) independent distribution system operator (IDSO), and (4) hybrid. Results from the cost benefit analysis suggests that large up-front costs would be required for their implementation, with net benefits to be captured shortly before 2039. The size of benefits depends strongly on a high level of DER uptake. It was recently concluded that there is no strong case to adopt any of the models in the short term [52]. The establishment of a local flexibility market is envisaged in the long term (i.e., the Wholesale Demand Respond Mechanism). Under this new scheme customers will have the opportunity to participate in the wholesale demand response market directly or via aggregators with a planned implementation date in October 2021. The mechanism proposes a new market participant category: demand response service provider (DRSP). Small customers have been excluded from the mechanisms, one of the main reasons is the cost of the extension of the mechanism to this kind of customer (i.e., imposition of higher costs to the whole system). Among other challenges are: behavioral demand response (not suitable for scheduling), difficulties in predicting counterfactual baseline and risk of distortionary consumer behavior [53].

In Great Britain, some respondents refer to the UK ENA Open Networks project where the design of flexibility markets is being evaluated under Workstream 1A (Flexibility Services). Seven products have been identified as part of this workstream and a recent consultation has been launched: Flexibility Consultation. Another respondent indicates that today there are enough market rules (with a particular reference to the procurement of flexibility BAU via a marketplace). Still another suggests that local market designs need to be rolled out via regulation to guarantee fair and transparent markets and better integration with existing markets. Yet, another makes remarks on the importance of establishing the roles and responsibilities of market players but suggests that doing this too early may represent a barrier.

The market design around flexibility markets remains a work in progress across the jurisdictions we look at. There remains a lot of experimentation and disagreement among market players. Interestingly the idea of market scenarios for the integration of DER into local distribution has been analysed in detail in the Australian context and rejected for now, this shows the dependency of sustainable flexibility markets on DER deployment. However, the non-emergence of a 'standard market design' does not preclude the role of the regulator in approving market designs.

\subsection{Specification of Rules for Peer-to-Peer Trading of Flexibility}

Only some of the respondents from GB agree that peer-to-peer (P2P rules) may play an important role in contracting flexibility by distribution utilities (see Table 7). In GB, the offering of non-DSO services (i.e., P2P) is being evaluated via the Open Networks Project (Product 6). The assessment of different trials (e.g., Transition, LEO, TraDER, Piclo Exchange and ReFLEX projects) will help to establish the best way distribution utilities can support non-DSO services.

$\mathrm{P} 2 \mathrm{P}$ rules that involve distribution utilities obligations that can facilitate flexibility trading to third parties, are not on the agenda in most of the jurisdictions. P2P is however already working in other sectors and its application to electricity remains of interest to many players. Distribution utilities can facilitate or act as intermediaries to secondary trading of flexibility (i.e., ancillary services) and also curtailment. Results from the different initiatives in GB that are testing non-DSO services will help to discover whether there is a relevant business model for these new services. 
Table 7. Specification of rules for peer-to-peer trading of flexibility-response summary.

\begin{tabular}{|c|c|c|c|c|c|c|c|}
\hline $\begin{array}{l}\text { Peer-to-Peer Trading } \\
\text { of Flexibility }\end{array}$ & $\mathbf{A U}$ & FR & DE & GB & $\mathrm{JP}$ & NL & NO \\
\hline \multicolumn{8}{|l|}{ already changed? } \\
\hline $\begin{array}{l}\text { Change being considered or } \\
\text { should be considered? }\end{array}$ & & & & yes & & & \\
\hline top 3 & & & & & & & \\
\hline
\end{tabular}

\subsection{Changes to Smart Meter Rules Framework}

Changes to smart meter regulation that may favour the use of flexibility has been reported in a few jurisdictions ( 3 out of 7). Respondents from four jurisdictions suggest that changes are being considered or should be considered (9 out of 18). Only one respondent from GB (distribution utility) places this change within their top (see Table 8).

Table 8. Changes to smart meter rules framework—-response summary.

\begin{tabular}{cccccccc}
\hline Smart Meter Rules Framework & AU & FR & DE & GB & JP & NL & NO \\
\hline already changed? & yes & yes & & & & & yes \\
\hline $\begin{array}{c}\text { change being considered or should } \\
\text { be considered? }\end{array}$ & yes & & yes & yes & yes \\
\hline top 3 & & yes & \\
\hline
\end{tabular}

In GB, a respondent states that access to smart meter data by distribution utilities is fundamental for low voltage (LV) visibility. Another draws attention to the role of smart meters in allowing automated control (e.g., for EVs) facilitating the affordability of EV flexibility. A different respondent points out the consideration of a code modification that allows distribution utilities to control smart meters to turn on/off EV charging in the case of a network emergency and also some modifications to half hourly settlement. However, a different respondent suggests that smart meters are not necessarily looked at for settlement or dispatch and acknowledges other alternatives to provide asset level monitoring. Other respondents from GB and abroad (mainly distribution utilities) support the fact that a change to smart meter rules should not be considered.

In France, the respondent notes the current roll out of smart meters and remarks that their deployment will facilitate the integration of flexibility at distribution level. While in Japan the respondent expresses a view that the revision of the Measurement Law (Act) might be considered. In The Netherlands, the respondent comments that an adaptation to the Meter Code is envisaged after the roll out of smart meters. This is because the allocation procedure (i.e., based on usage profiles) would need to be adapted to actual usage instead (registered by the smart meter). A respondent from Norway points out that the smart meter rules came out in 2011 and that since 2019 all end-consumers have them installed (2.9 m).

We found mixed opinions across parties about the consideration of changes to smart meter framework. There was a residual suggestion that in exceptional circumstances DSOs should be able to control EV charging.

\subsection{Changes to Rules for Independent Agregators}

Changes have been reported only in one jurisdiction. France is the other one, however it has not been reported directly in the table. Respondents from four jurisdictions (9 out of 18) suggest that changes are currently in evaluation or should be considered. Only Japan places rules for independent aggregators as top 3 (see Table 9). 
Table 9. Changes to rules for independent aggregators—response summary.

\begin{tabular}{|c|c|c|c|c|c|c|c|}
\hline $\begin{array}{c}\text { Rules for Independent } \\
\text { Aggregators }\end{array}$ & AU & FR & $\mathrm{DE}$ & GB & $\mathrm{JP}$ & NL & NO \\
\hline already changed? & & & yes & & & & \\
\hline $\begin{array}{l}\text { change being considered or should } \\
\text { be considered? }\end{array}$ & yes & & yes & yes & yes & & \\
\hline top 3 & & & & & yes & & \\
\hline
\end{tabular}

In Australia, one respondent points out different initiatives (including consultations) that involve potential changes to the roles (or new roles) and market participation of aggregators. There are different initiatives such as the 2-sided market proposal (i.e., definition and roles of "traders", see [51]), wholesale demand response (i.e., new market participant: demand response aggregator-DRA) and wholesale market only (i.e., new market participant: small generation aggregator-SGA).

A respondent from France, notes that in comparison with other EU member states France is already a step further in terms of independent aggregators which can freely participate in all its markets, including in demand side response with specific rules for this. It is expected that the demand side flexibility code does not conflict with the existing rules. The European Commission has identified demand side flexibility as one of the two key areas where new network codes could be required to achieve the European Green Deal goals.

In GB one respondent suggests that aggregators have made limited progress in flexibility markets. It is also acknowledged by a different respondent that distribution utilities should not act as mandated commercial aggregators and that the adaptation to industry codes to facilitate access to markets by independent aggregators is needed. Wider Access changes to the Balancing and Settlement Code-BSC (Modification P344) have allowed the participation of independent aggregators in the Balancing Mechanism (BM), previously they could also participate but via a supplier.

In Japan, one respondent states that there are no legal restrictions on aggregators, and an aggregator license has been evaluated by the Expert Committee. Another response points out the release and recent revision of the Guidelines for Energy Resource Aggregation Business (ERAB).

In The Netherlands, the respondent indicates that changes to the current framework for independent aggregators have already been evaluated and that the rules were found to be adequate and no changes were proposed. According to the respondent there are conflicts between aggregators and energy suppliers that aggregate individual connections across Balance Responsible Parties (BRPs).

Aggregators play an important role in the procurement of flexibility, especially from small-scale DER which may otherwise be prevented (depending on the size) from participating in different markets, such as wholesale, ancillary services markets, etc. Apart from in France, who were the pioneers in allowing aggregators to participate in all markets, it is observed that rules about independent aggregators are evolving and some conflicts with other parties may exist. Australia and GB have introduced new market participants oriented to independent aggregators, with the aim of encouraging their participation. There is some variation across jurisdictions in the extent to which changes are needed to facilitate the participation of independent aggregators in flexibility markets and reduce the chance of conflicts with other players (i.e., with retailers).

\subsection{Encouragement of Better Interaction/Coordination between Electricity Distribution and Transmission System Operators}

Respondents from three jurisdictions indicate that some changes to encourage better coordination between distribution utilities and system operators have been already made. Other respondents remark on current consideration of changes or their agreement that they 
should be considered in future regulation. Respondents from Australia, Great Britain and Norway (7 out of 18) rank this change within the top 3, see Table 10.

Table 10. Encouragement of better interaction/coordination between DSOs and TSOs-response summary.

\begin{tabular}{|c|c|c|c|c|c|c|c|}
\hline $\begin{array}{l}\text { Interaction/Coordination } \\
\text { between DSOs and TSOs }\end{array}$ & AU & FR & DE & GB & $\mathrm{JP}$ & NL & NO \\
\hline already changed? & yes & yes & & yes & & & \\
\hline $\begin{array}{l}\text { change being considered or should } \\
\text { be considered? }\end{array}$ & yes & & & yes & & yes & yes \\
\hline top 3 & yes & & & yes & & & yes \\
\hline
\end{tabular}

A respondent from Australia points out that this change was evaluated but no agreement was agreed between distribution utilities and the system operator. They pointed to unresolved and live tensions between the decentralised and centralized approaches and the intention of the system operator to plan and operate distribution networks. A different respondent states that they are working with the transmission network business where flexibility is considered as part of their joint planning.

A different perspective is noted in The Netherlands. There has been evaluation of a joint proposal by all grid operators with respect to congestion management in lower voltage grids. The proposal aims to clarify products and processes for a more cost-efficient deployment of flexibility and suggests the introduction of a new role: the congestion service provider (CSP), with the ability to aggregate small-scale flexibility.

In Germany, one of the respondents mentions an ongoing process for better coordination. In Japan, the need for coordination was not recognised because distribution operation and transmission operation are bundled (i.e., in the form of regional network companies). According to the respondent, an important decision has been recently made proposing the creation of independent distribution network operators. This means that a separation of $\mathrm{D}$ and $\mathrm{T}$ is envisaged. In Norway, one respondent points out an ongoing project that aims to assess the current operating practices and coordination between the transmission system operator, regional and local network operators and other key actors. An expert group has been appointed to undertake a study, for details see [54]. The regulator has asked the industry for inputs to the expert group's recommendations. Another respondent suggests that due to the transition to more decentralised systems, the distribution utility is the most suitable party to address any issues (i.e., network constraint) in its network.

In France, it was suggested that coordination is needed because flexibility can be required at the same grid location and needs to be addressed at different voltage levels. It was also noted that better coordination optimises the participation of market players and facilitates stacking of revenue streams from both parties, improving market liquidity.

In Great Britain, most respondents agree about the need for better coordination between distribution network operators and the system operator and the role of timely regulation in this. According to them better coordination brings benefits such as system efficiency, further market opportunities, more liquidity (i.e., revenue stacking from different markets at distribution and transmission system levels), more competition, the avoidance of conflict of interest (i.e., between transmission and distribution actions), identification of key operational issues (and their origin) due to information exchange, etc. The introduction of coordination obligations in the forthcoming price control (RIIO-ED2) was also mentioned. This refers to the introduction of a whole system reopener called Coordinated Adjustment Mechanism (CAM) proposed in the RIIO-2 Sector Specific Methodology [55]. The introduction of CAM is part of the whole system approach and a modification of the system licence conditions for electricity distribution utilities and transmission owners is also under evaluation. According to the GB energy regulator [56] (p. 126), CAM is defined as follows: "A whole system focused re-opener to protect consumer interests by supporting the 
reallocation of project revenues and responsibilities to the network best placed to deliver the relevant projects." There are no financial incentives for distribution utilities to use the CAM. The exploration of whole system options is expected to be BAU.

Coordination between key parties such as distribution utilities and TSOs or system operators is vital. Many of the respondents have expressed different levels of and ways of promoting coordination in their respective jurisdictions, including the new approach in RIIO-ED2 in GB. With some exceptions, such as Japan and Australia, coordination rules are still a work in progress and very much supported by the electricity sector and electricity regulators. Better coordination brings many benefits (i.e., system efficiency, better visibility of DER assets, data exchange, better planning and investment co-ordination, etc.). It involves the coordination of flexibility markets to maximise benefits (who is in charge of what, types of products to procure, etc.). This coordination should start with those able to contract for flexibility and involve integration into existing transmission level markets where appropriate.

\subsection{New Rules That Allow Distribution Utilities to Procure Flexibility on Behalf of Transmission} Level System Operators

This type of change elicits less consensus across the parties with only some indication that it should considered in two jurisdictions. Only two respondents (out of 18) place this within their top 3 (see Table 11).

Table 11. Rules that allow distribution utilities to procure flexibility on behalf of transmission level system operators-response summary.

\begin{tabular}{|c|c|c|c|c|c|c|c|}
\hline $\begin{array}{l}\text { Distribution Utilities to Procure } \\
\text { Flexibility Services on Behalf of TSOs }\end{array}$ & $\mathbf{A U}$ & FR & $\mathrm{DE}$ & GB & $\mathrm{JP}$ & NL & NO \\
\hline \multicolumn{8}{|l|}{ already changed? } \\
\hline $\begin{array}{l}\text { Change being considered or should } \\
\text { be considered? }\end{array}$ & yes & & & yes & & & \\
\hline top 3 & & & & yes & & & \\
\hline
\end{tabular}

A respondent from The Netherlands points out that a collaboration between the two parties is envisaged instead. In GB, one respondent suggests that this role has been evaluated (in ENA World A) but no decision/implementation has been made. Another respondent supports this approach and suggests that distribution utilities should be able to access transmission level flexibility if is the most cost-efficient solution.

Perhaps surprisingly, this is not seen as a big issue among our jurisdictions. This is possibly because as of now DSOs and TSOs are currently operating in different markets for flexibility. However, there is some hint that at some point they may begin to compete with one another to provide services to support the electricity grid which will raise issues to do with jurisdiction and control hierarchy, along the lines suggested by [57].

\subsection{Changes to Feed-in-Tariff Regulation}

Changes to feed-in-tariff regulation is one of the changes that has already been made in five jurisdictions according to many participants. Participants from four jurisdictions state that a change in being considered or should be considered. In only two jurisdictions changes to feed-in-tariff regulation is placed in the top 3 (see Table 12).

In GB one respondent reports a recent change- the introduction of the smart export guarantee (SEG) — which offers a payment to small scale low carbon generators for electricity exported to the grid. Another respondent suggests that export/self-consumption should be maximised from FIT assets. A third indicates the end of the scheme in March 2019 and that no changes are being considered now. 
Table 12. Changes to feed-in-tariff regulation- response summary.

\begin{tabular}{cccccccc}
\hline Feed-in-Tariff Regulation & AU & FR & DE & GB & JP & NL & NO \\
\hline already changed? & yes & yes & & yes & yes & yes & \\
\hline $\begin{array}{c}\text { change being considered or should } \\
\text { be considered? }\end{array}$ & yes & yes & & yes & & & yes \\
\hline top 3 & & & & & yes & & yes \\
\hline
\end{tabular}

In Japan, one respondent communicates a recent change: the adoption of Feed-inPremium-FIP (in addition to the existing FIT). In The Netherlands, the respondent references the SDE++ (Stimulation of Sustainable Energy Transition scheme), based on a Feed-in-Premium and also a regulation applicable to residential customers with solar panels where customers are allowed to offset the amount of electricity consumed with electricity produced. It is acknowledged that due to the avoidance of different charges by these customers (i.e., energy taxes) inter alia, the government has announced the end of the scheme.

Feed-in-tariff schemes have been implemented some time ago and the mechanism has evolved too. An example of this is the Feed-in-Premium (FIP) that introduced a market-based component in the price or compensation given to the owner of renewable generator (or other type of low carbon asset), such as SDE++ from the Netherlands. Current changes or future changes to feed-in-tariffs that encourage the use of flexibility have been acknowledged by a few respondents. In most cases, it is not clear how to easily incentivise participation in flexibility markets by small FiT generators, considering the fixed amount that owners of DER are entitled to via their original feed-in-tariff scheme. Ideally the decision to opt for flexibility should be driven by the market however, this is not always the case. For instance, in Germany CHP plants receive a generous allowance in the form of direct support scheme incentives, avoided network tariffs and income from providing heating, all of which bypass the true electricity price signal ( $16 \%$ of electricity consumption is generated via CHP plants in Germany).

\subsection{Improvements to Customer Data Management and Access}

Changes to the rules regarding customer data management and access have been acknowledged in only two jurisdictions. However, respondents from most jurisdictions have confirm current changes are being considered or agree that these should be considered, with a high level of consensus (15 out of 18 respondents). Respondents from four jurisdictions have placed this change within the top 3 . Table 13 shows the results.

In Australia, one respondent comments on a recent consultation from [58] about the minimum DER technical requirements (DER are largely unmonitored and uncoordinated as of now), including interoperability requirements (which includes data monitoring and exchanges, communication capabilities, and controllability/coordination). The consultation is a response to the recent recommendation made by the Energy Security Board (ESB) in March 2020 to put in place minimum DER technical standards by October 2020. Another respondent discusses the limitations that distribution utilities have on customer flexibility data, and the limitations that customers have to capture the value of flexibility.

The respondent from France notes that the implementation of flexibility at lower voltages requires the analysis of key data (i.e., load curve, geographical position, etc.), which is also useful to improve sourcing of sites by DER. In Japan, one respondent points out the need for a common social platform to visualise available capacity and location of DER to make the best use of DER. While in Norway, it was suggested that centralisation and data access is essential if we are to move to a more automated and integrated energy system. 
Table 13. Improvements to customers data management and access—response summary.

\begin{tabular}{cccccccc}
\hline $\begin{array}{c}\text { Customer Data Management } \\
\text { and Standardisation }\end{array}$ & AU & FR & DE & GB & JP & NL & NO \\
\hline $\begin{array}{c}\text { already changed? } \\
\begin{array}{c}\text { change being considered or should } \\
\text { be considered? }\end{array}\end{array}$ yes & yes & yes & yes & yes & yes \\
\hline top 3 & yes & yes & & yes & yes \\
\hline
\end{tabular}

In The Netherlands there is an upcoming broad array of changes to current data management regulation to be introduced in the Energy Law 1.0 (which integrates the current Electricity Law, Gas law and Clean Energy Package legislation). The respondent advocates additional changes in data management as part of the adaption of the network code (i.e., submission of production/consumption data to grid operators for the next day), however there are some concerns regarding the predictions from grid users and difficulties in determining the baseline from which to measure flexibility. As a result, distribution utilities still rely on internal grid models (i.e., congestion forecasting).

In Great Britain, the Energy Data Taskforce report was mentioned [59], where a set of recommendations currently at various stages of implementation have been provided, regarding the way in which government and industry can combine efforts to unlock system benefits and to maximise customer benefits. As a result of those recommendations, the regulator requires network companies to undergo effective digitalisation and discuss their digitalisation strategies in their Business Plans. Two licence obligations will be introduced for distribution utilities in RIIO-ED2: (1) the publication of updated companies' Digitalisation Strategy \& Action Plan and on (2) the use of data. Another respondent points out that as part of the distribution utilities' privacy plans, they are required to prepare data privacy plans which state the way in which they would anonymise the data, including the expected benefits from access to data. However, access to smart meter data due to privacy issues was also noted by one respondent, suggesting that distribution utilities in GB are forbidden from accessing a single user's data and must rely on suppliers or aggregators to bring domestic participation to market.

There is consensus that data is a key enabler especially at lower voltages. The initiatives described above confirm this. Technological advances (i.e., digitalisation) can facilitate this but regulatory intervention is needed to set obligations, including technical requirements (i.e., interoperability). We observe that the rules regarding data management and access (including DER data) are being set out in different regulatory documentation/consultations and Energy Laws. Lack of data (or access to it) may have an adverse impact on the establishment of more robust regulation that promotes the use of flexibility. For instance, regulators may prefer to exclude the implementation of new rules due to data non-availability or inaccuracy. Reciprocity is important too, so that not only distribution utilities can benefit from this (i.e., better planning, cost efficient investments, better visibility, etc.) but also end customers.

\subsection{Creation of Standard Cost Benefit Methodology for the Evaluation of Flexibility Services at Distribution Level}

No jurisdiction we looked at has reported the introduction of a common methodology to evaluate flexibility at the distribution level. However, respondents from four jurisdictions (9 out of 18) report ongoing discussions where it is being considered or agree that the introduction of the methodology should be considered, see Table 14 . 
Table 14. Creation of standard cost benefit methodology for the evaluation of flexibility services at distribution level—response summary.

\begin{tabular}{cccccccc}
\hline $\begin{array}{c}\text { Standard Methodology for Evaluating } \\
\text { Flexibility at Distribution }\end{array}$ & AU & FR & DE & GB & JP & NL & NO \\
\hline already changed? & & & & & & \\
\hline $\begin{array}{c}\text { Change being considered or should } \\
\text { be considered? }\end{array}$ & yes & & yes & yes & & & yes \\
\hline top 3 & yes & yes & yes & & & \\
\hline
\end{tabular}

In Australia, respondents note a proposal to assess the value of DER integration (VaDER), which aims to provide a common framework to evaluate the costs incurred by distribution utilities to accommodate DER on their networks. The study also considers the societal impact such as carbon reduction benefits [60].

A respondent from Germany points out that incentives for the use of flexibility by distribution utilities are poor or non-existent. There is a need for a clear incentive to claim costs for flexibility procurement (i.e., via regulated opex) and for more guidance on a cost benefit analysis (CBA) methodology that would be accepted by the regulator.

Respondents from GB confirm the proposal of a new flexibility methodology developed by the Open Networks Project, along with other key products. The methodology takes into account networks costs and the value of reinforcement deferral, wider network and societal impacts (e.g., network losses, changes in CMLs and CI driven by the asset condition, carbon emissions, etc.), [61]. One respondent notes the importance of having a common methodology to reduce risks of under or over pricing that may produce an adverse impact on flexibility providers or consumers. The respondent also suggests that even though there are indicative prices for flexibility published by distribution utilities (i.e., via Piclo), there is no common methodology yet in place that can explain future price risk.

In The Netherlands, it is reported that no standard methodology has been created or is under consideration by the regulator. However, an initiative from a working group of network users and distribution utilities is noted. The working group has developed a methodology that assists distribution utilities to evaluate flexible solutions versus more traditional alternatives. The proposed method ensures that the solution is deployed with the lowest socialised costs. According to the working group, the idea is that the distribution utilities take this methodology into consideration in their capacity planning process.

In Norway, one respondent states that a methodology that considers flexibility is already in place as part of the requirements of the biannual investment planning report from the distribution utilities. A different respondent remarks on the importance of having a common methodology to encourage the distribution utility to procure flexibility in local markets and to increase economic welfare. A different approach is observed in France. The respondent suggests that the CBA will depend on the grid structure or topology of the distribution utility which may be exposed to different risks and policies.

A common cost benefit methodology for evaluating flexibility solutions versus traditional ones (i.e., network reinforcement, others) is important and should be a joint work between key energy stakeholders, including the energy regulator. We observe that most of our jurisdictions are working on or have already proposed a kind of methodology that aims to promote the use of flexibility as part of BAU solutions. Having a common methodology that can be used by distribution utilities is crucial, adds transparency to decision making and should be aligned (if applicable) with any other that the regulator or other energy authority have developed. It is important that the methodology also considers societal benefits and is technologically agnostic. For instance, in GB the methodology is aligned with the CBA tool for network investment decisions that the regulator applies to distribution utilities in their evaluation of business plans, but it is not yet fully aligned with the central government's Green Book methodology for public policy appraisal [62]. 


\section{Summary Findings and Conclusions}

This paper explores different regulatory changes that may be required to incentivise the use of flexibility by distribution utilities in 7 jurisdictions. This flexibility, in the form of specific services that can help for instance to solve network constraints, can be provided by different types of distributed energy resources. The better integration of them, supported by suitable regulation, may encourage distribution utilities to adopt more flexible solutions offered by third parties in order to solve grid issues.

A couple of questionnaires were sent to key parties including energy regulators, distribution utilities, energy associations and energy marketplace platforms to capture their views. We received and evaluated 18 responses. We acknowledge that one of the limitations of this study is the number of responses, however we note that this is not a representative survey and that what we seek is a general impression of the main regulatory issues identified by the respondents within their jurisdictions. The evaluation of diverse perspectives is what we stress in this study.

We would suggest that there is much that can be learned from the experience and analysis arising from the six other jurisdictions with respect to flexibility markets, even for a leading jurisdiction such as Great Britain. We would highlight the following.

First, even where flexibility markets (e.g., in The Netherlands) are highly developed and incentives - in the form of the DSO revenue model and tariff structure- exist it remains unclear as to whether they are cost effective at a sustainable scale and whether current regulation is fit for purpose (i.e., does not penalise the adoption of flexible solutions when it seems the most cost-efficient option).

Second, more dynamic network tariffs have been or are being considered in several jurisdictions, but all jurisdictions remain cautious as to the practicality of their implementation (even in France which has a single large DSO capable of widely socializing the impact across all non-flexible customers). What we would expect is that network tariff design would not deter the provision of flexibility services by those that want to offer them.

Third, while there are moves across multiple jurisdictions to specify and standardize flexibility products it remains unclear as to whether this is the optimal way to handle customer willingness to pay which is not a function of the flexibility product but of its characteristics.

Fourth, the market design of flexibility markets is a work in progress, and we remain in an experimentation phase. Sophisticated market designs are being considered and, in some cases, do not appear to pass a cost benefit test (such as the different market scenarios proposed to integrate DER into local distribution networks in Australia). What seems to be an issue is the locational nature of some flexibility services which can deter competition and reduce market liquidity. A larger deployment of DER and more participation from them could change this in the future.

Fifth, there is little interest across our jurisdictions in peer-to-peer trading as an issue in current debates about flexibility markets. The focus, outside GB, remains on procurement by the DSO to meet its own needs.

Sixth, the facilitation of increased co-ordination between TSOs and DSOs is actively being pursued across most of the jurisdictions where unbundling is in place. Australia exhibits some signs of active conflict between the TSOs and DSOs in some areas which needs to be addressed. There is therefore a clear need for further regulatory guidance especially related to data sharing between DSOs and TSOs for optimal network operation and stacking of revenues (in different or within the same timescales).

Seventh, allowing DSOs to procure flexibility on behalf of the TSO is not seen as a big issue outside of GB. However, this is somewhat surprising and reflects the fact that currently DSOs and TSOs are procuring very different types of flexibility and trying to avoid direct competition or even direct contractual relationships. It is not clear how sustainable this avoidance of conflict (and its resolution) is in the longer run.

Finally, most of jurisdictions are working on a common cost benefit methodology (of the type that already exists in New York) to evaluate flexibility solutions. There is clearly 
a need for this and for it to be consistent with standard social cost benefit methodologies being used by central and local government.

Author Contributions: Conceptualisation: K.L.A., M.G.P.; methodology, formal analysis, investigation, writing—original draft preparation: K.L.A.; writing—review and editing: M.G.P. All authors have read and agreed to the published version of the manuscript.

Funding: The authors acknowledge the financial support of SSEN via BEIS funded Power Forward Challenge-Pilot Scale Demonstration scheme.

Acknowledgments: The authors acknowledge the support of the Project MERLIN (Modelling the Economic Reactions Linking Individual Networks) led by Scottish and Southern Electricity Networks (SSEN). We wish to thank Rhys Williams and colleagues at SSEN for their comments and support. The authors also acknowledge valuable inputs from energy regulators, distribution electricity companies, independent market platforms, energy networks associations and energy experts that agreed to take part in the survey. All remaining errors are those of the authors.

Conflicts of Interest: The authors declare no conflict of interest.

$\begin{array}{ll}\text { Abbreviations } \\ \text { ACM } & \text { Authority for Consumers \& Markets } \\ \text { AEMO } & \text { Australian Energy Market Operator } \\ \text { AEMC } & \text { Australian Energy Market Commission } \\ \text { AER } & \text { Australian Energy Regulator } \\ \text { ARENA } & \text { Australian Renewable Energy Agency } \\ \text { CAM } & \text { Coordinated Adjustment Mechanism } \\ \text { DEIP } & \text { Distributed Energy Integration Program } \\ \text { DER } & \text { Distributed Energy Resources } \\ \text { DNO } & \text { Distribution Network Operator } \\ \text { DSO } & \text { Distribution System Operator } \\ \text { DNSP } & \text { Distribution Network Service Provider } \\ \text { ENA } & \text { Energy Networks Association } \\ \text { ESB } & \text { Energy Security Board } \\ \text { GOPACS } & \text { Grid Operators Platform for Congestion Solutions } \\ \text { MERLIN } & \text { Modelling the Economic Reactions Linking Individual Networks } \\ \text { METI } & \text { Minister for Economy, Transport and Infrastructure-Japan } \\ \text { NEM } & \text { National Electricity Market } \\ \text { NVE } & \text { Norwegian Water Resources and Energy Directorate } \\ \text { OFGEM } & \text { Office of Gas and Electricity Markets } \\ \text { SINTEG } & \text { Schaufenster intelligente Energie-Digitale Agenda für die Energiewende } \\ & \text { (Smart energy showcases-Digital agenda for the energy transition) } \\ \text { SSEN } & \text { Scottish and Southern Electricity Networks } \\ \text { TSO } & \text { Transmission System Operator } \\ \text { VPP } & \text { Virtual Power Plant } \\ \text { WEM } & \text { Wholesale Electricity Market } \\ & \end{array}$

Appendix A. List of Participants

\begin{tabular}{|c|c|c|c|c|}
\hline Country & Organisation/Party & Type of Party & General View & Project/Initiative Specific \\
\hline \multirow[t]{3}{*}{ Australia } & Ausgrid & distribution utility & & yes (Ausgrid's Battery VPP) \\
\hline & ENA & energy association & yes & \\
\hline & $\begin{array}{l}\text { Australian Energy } \\
\text { Regulator-AER }\end{array}$ & regulator & yes & \\
\hline France & Enedis & distribution utility & yes & \\
\hline \multirow[t]{2}{*}{ Germany } & Avacon & distribution utility & & yes (Avacon-InterFLEX project) \\
\hline & Bnetza & regulator & yes & \\
\hline
\end{tabular}




\begin{tabular}{|c|c|c|c|c|}
\hline Country & Organisation/Party & Type of Party & General View & Project/Initiative Specific \\
\hline \multirow[t]{7}{*}{ Great Britain } & SSEN & distribution utility & & $\begin{array}{l}\text { yes (flexibility services in } \\
\text { Constraint Managed Zones) }\end{array}$ \\
\hline & WPD & distribution utility & & $\begin{array}{l}\text { yes (flexibility services: } \\
\text { Flexible Power) }\end{array}$ \\
\hline & UK Power Networks & distribution utility & & $\begin{array}{l}\text { yes (flexibility services: } \\
\text { Flexible Hub) }\end{array}$ \\
\hline & $\begin{array}{l}\text { Cornwall Local Energy } \\
\text { Market_LEM (Centrica) }\end{array}$ & marketplace & & $\begin{array}{c}\text { yes (marketplace for the } \\
\text { procurement of } \\
\text { flexibility services) }\end{array}$ \\
\hline & Piclo Flex (Piclo) & marketplace & & $\begin{array}{c}\text { yes (marketplace for the } \\
\text { procurement of } \\
\text { flexibility services) }\end{array}$ \\
\hline & Ofgem & energy regulator & yes & \\
\hline & ENA & energy association & yes & \\
\hline \multirow[t]{2}{*}{ Japan } & Tepco & distribution utility & & $\begin{array}{l}\text { yes (V2G Demonstrator project } \\
\text { using EVs and VPP resources) }\end{array}$ \\
\hline & Expert & energy expert & yes & \\
\hline Netherlands & $\begin{array}{c}\text { Authority for Consumers and } \\
\text { Markets-ACM }\end{array}$ & regulator & yes & \\
\hline \multirow[t]{2}{*}{ Norway } & $\begin{array}{c}\text { Norwegian Energy Regulatory } \\
\text { Authority (NVE-RME) }\end{array}$ & regulator & yes & \\
\hline & Nodes & marketplace & & $\begin{array}{l}\text { yes (marketplace for the } \\
\text { procurement of flexibility } \\
\text { services) }\end{array}$ \\
\hline
\end{tabular}

Appendix B. Questionnaires

Questionnaire 1

Regulation and new roles of electricity distribution utilities, other parties and markets

1. How is your jurisdiction actively encouraging a move towards competitive procurement of flexibility services at the distribution level? (e.g., innovation trials, changes to regulation, changes to regulatory incentives).

2. What lessons, if any, have been learned about changes to regulatory arrangements which would encourage more competitive procurement of flexibility services at the distribution level in your jurisdiction? Please fill in the table below.

\begin{tabular}{|c|c|c|c|c|}
\hline $\begin{array}{c}\text { Potential } \\
\text { Regulatory Change }\end{array}$ & $\begin{array}{c}\text { Already Changed } \\
(\text { Yes/No) }\end{array}$ & $\begin{array}{c}\text { Change Being } \\
\text { Considered (Yes/No) }\end{array}$ & Top 3 in Your View & $\begin{array}{c}\text { Short Explanation } \\
\text { (Top } 3 \text { Only) }\end{array}$ \\
\hline \multicolumn{5}{|l|}{$\begin{array}{l}\text { Changes to utilities' } \\
\text { revenue incentives }\end{array}$} \\
\hline \multicolumn{5}{|l|}{$\begin{array}{l}\text { Changes to network } \\
\text { tariff structure }\end{array}$} \\
\hline $\begin{array}{l}\text { Changes to definition of } \\
\text { products/service } \\
\text { standardisation }\end{array}$ & & & & \\
\hline
\end{tabular}




\begin{tabular}{|c|c|c|c|c|}
\hline $\begin{array}{c}\text { Potential } \\
\text { Regulatory Change }\end{array}$ & $\begin{array}{l}\text { Already Changed } \\
(\text { Yes/No) }\end{array}$ & $\begin{array}{c}\text { Change Being } \\
\text { Considered (Yes/No) }\end{array}$ & Top 3 in Your View & $\begin{array}{l}\text { Short Explanation } \\
\text { (Top } 3 \text { Only) }\end{array}$ \\
\hline \multicolumn{5}{|l|}{$\begin{array}{l}\text { Specification of market } \\
\text { design for local } \\
\text { flexibility markets }\end{array}$} \\
\hline \multicolumn{5}{|l|}{$\begin{array}{l}\text { Specification of rules for peer } \\
\text { to peer trading of flexibility }\end{array}$} \\
\hline \multicolumn{5}{|l|}{$\begin{array}{l}\text { Changes to smart meter } \\
\text { rules framework }\end{array}$} \\
\hline \multicolumn{5}{|l|}{$\begin{array}{l}\text { Changes to rules for } \\
\text { independent aggregators }\end{array}$} \\
\hline \multicolumn{5}{|l|}{$\begin{array}{l}\text { Encouragement of better } \\
\text { interaction/ coordination } \\
\text { between electricity } \\
\text { distribution and } \\
\text { transmission } \\
\text { system operators }\end{array}$} \\
\hline \multicolumn{5}{|l|}{$\begin{array}{l}\text { New rules that allow } \\
\text { distribution utilities to } \\
\text { procure flexibility on behalf } \\
\text { of transmission level } \\
\text { system operators }\end{array}$} \\
\hline \multicolumn{5}{|l|}{$\begin{array}{l}\text { Changes to feed-in- } \\
\text { tariff regulation }\end{array}$} \\
\hline \multicolumn{5}{|l|}{$\begin{array}{l}\text { Improvements to customer } \\
\text { data management and access }\end{array}$} \\
\hline \multicolumn{5}{|l|}{$\begin{array}{l}\text { Creation of standard cost } \\
\text { benefit methodology for the } \\
\text { evaluation of flexibility } \\
\text { services at distribution level }\end{array}$} \\
\hline Other(s)? (Please specify): & & & & \\
\hline
\end{tabular}

3. In evaluating flexibility bids/offers, which of the following non-monetary/difficult to quantify aspects may be taken into account by electricity distribution system operators?

\begin{tabular}{|c|c|c|c|}
\hline Value Stream & Already Allowed (Yes/No) & Being Considered (Yes/No) & Comments (If Any) \\
\hline \multicolumn{4}{|l|}{ Carbon reduction } \\
\hline \multicolumn{4}{|l|}{ Road traffic/street level impact } \\
\hline \multicolumn{4}{|l|}{$\begin{array}{l}\text { Community scheme (e.g., as per } \\
\text { Community Credit in New York) }\end{array}$} \\
\hline \multicolumn{4}{|l|}{ Value of resilience } \\
\hline Other(s)? (Please specify) & & & \\
\hline
\end{tabular}

Please do refer us to any published regulatory documents that you think would be particularly helpful for our study.

Questionnaire 2

\section{Potential Regulatory Changes}

1. Based on the experience of [your project/initiative], what are the most relevant changes on regulation that would be necessary to facilitate and accelerate the trading of flexibility services by electricity distribution utilities (from distributed energy resources-DER, commercial/residential customers, etc.)? 


\begin{tabular}{|c|c|c|c|}
\hline Potential Regulatory Change & $\begin{array}{l}\text { Should Be Considered } \\
\text { (Yes/No) }\end{array}$ & Top 3 in Your View & $\begin{array}{l}\text { Short Explanation } \\
\text { (Top } 3 \text { Only) }\end{array}$ \\
\hline \multicolumn{4}{|l|}{ Changes to utilities' revenue incentives } \\
\hline \multicolumn{4}{|l|}{ Changes to network tariff structure } \\
\hline \multicolumn{4}{|l|}{$\begin{array}{l}\text { Changes to definition of } \\
\text { products/service standardisation }\end{array}$} \\
\hline \multicolumn{4}{|l|}{$\begin{array}{l}\text { Specification of market design for local } \\
\text { flexibility markets }\end{array}$} \\
\hline \multicolumn{4}{|l|}{$\begin{array}{l}\text { Specification of rules for peer to peer trading } \\
\text { of flexibility }\end{array}$} \\
\hline \multicolumn{4}{|l|}{ Changes to the smart meter rules framework } \\
\hline \multicolumn{4}{|l|}{ Changes to rules for independent aggregators } \\
\hline \multicolumn{4}{|l|}{$\begin{array}{l}\text { Encouragement of better interaction/ } \\
\text { coordination between electricity distribution and } \\
\text { transmission system operators }\end{array}$} \\
\hline \multicolumn{4}{|l|}{$\begin{array}{l}\text { New rules that allow distribution utilities to } \\
\text { procure flexibility on behalf of transmission level } \\
\text { system operators }\end{array}$} \\
\hline \multicolumn{4}{|l|}{ Changes to feed-in-tariff regulation } \\
\hline \multicolumn{4}{|l|}{$\begin{array}{l}\text { Improvements to customer data management } \\
\text { and access }\end{array}$} \\
\hline \multicolumn{4}{|l|}{$\begin{array}{l}\text { Creation of standard cost benefit methodology } \\
\text { for the evaluation of flexibility services at } \\
\text { distribution level }\end{array}$} \\
\hline Other(s)? (Please specify): & & & \\
\hline
\end{tabular}

Please do refer us to any published regulatory documents that you think would be particularly helpful for our study.

\section{References}

1. Pereira, G.I.; Pereira da Silva, P.; Cerqueira, P.A. Electricity distribution incumbents' adaptation toward decarbonized and smarter grids: Evidence on the role market, regulatory, investment and firm-level factors. Energy Policy 2020, 142, 111477. [CrossRef]

2. European Commission. Clean Energy for All Europeans Package; European Commission: Brussels, Belgium, 2019.

3. Anaya, K.L.; Pollitt, M.G. How to procure flexibility services within the electricity distribution system: Lessons from an international review of innovation projects. Energies 2021. not published.

4. Anaya, K.L.; Pollitt, M.G. MERLIN Milestone 3: Regulation and Policies for Local Flexibility Markets: Current and Future Developments in Seven Leading Countries; Scottish and Southern Electricity Networks: Perth, Scotland, 2020.

5. Anaya, K.L.; Pollitt, M.G. MERLIN Milestone 1: A Review of International Experience in the Use of Smart Electricity Platforms for the Procurement of Flexibility Services (Part 1); Scottish and Southern Electricity Networks: Perth, Scotland, 2020.

6. Spiliotis, K.; Ramos Gutierrez, A.I.; Belmans, R. Demand flexibility versus physical network expansions in distribution grids. Appl. Energy 2016, 182, 613-624. [CrossRef]

7. Pollitt, M.G. Electricity network charging in the presence of distributed energy resources: Principles, problems and solutions. Econ. Energy Environ. Policy 2018, 7, 89-103. [CrossRef]

8. Faerber, L.A.; Balta-Ozkan, N.; Connor, P.M. Innovative network pricing to support the transition to a smart grid in a low-carbon economy. Energy Policy 2018, 116, 210-219. [CrossRef]

9. Brown, D.P.; Sappington, D.E.M. On the role of maximum demand charges in the presence of distributed generation resources. Energy Econ. 2018, 69, 237-249. [CrossRef]

10. European Commission. Demand Side Flexibility. Perceived Barriers and Proposed Recommendations; European Smart Grids Task Force Expert Group 3: Brussels, Belgium, 2019.

11. Bergaentzlé, C.; Jensen, I.G.; Skytte, K.; Olsen, O.J. Electricity grid tariffs as a tool for flexible energy systems: A Danish case study. Energy Policy 2019, 126, 12-21. [CrossRef]

12. Commission de Régulation de L'énergie. Activity Report 2017; CRE: Paris, France, 2018.

13. Ministry of Economy, Trade and Industry. Electricity System and Market in Japan; METI: Tokyo, Japan, 2018. 
14. Alliander. Annual Report 2018. Moving forward Together; Alliander N.V.: AH Arnhem, The Netherlands, 2019.

15. BnetzA. Monitoring Report 2019; Bundesnetzagentur: Bonn, Germany, 2019.

16. Enedis, Key Figures. Available online: https:/ / www.enedis.fr/notre-entreprise (accessed on 28 May 2021).

17. Japan Electric Power Information Center. The Electric Power Industry in Japan 2019; JEPIC: Tokyo, Japan, 2019.

18. Flataker, O.; Nielsen, H.H. National Report 2019; No 33/2019; The Norwegian Water Resources and Energy Directorate (NVE): Oslo, Norway, 2019.

19. Tokyo Electric Power Company Holdings. TEPCO Integrated Report 2019; Tepco: Tokyo, Japan, 2019.

20. UK Power Networks. Data Privacy Plan for Access to Smart Meter Consumption Data; UK Power Networks: London, UK, 2019.

21. Australian Energy Regulator. State of the Energy Market 2020; AER: Melbourne, Australia, 2020.

22. Council of European Energy Regulators. CEER Paper on Electricity Distribution Tariffs Supporting the Energy Transition. Distribution Systems; Working Group, CEER: Brussels, Belgium, 2020.

23. EDF. Robust 2019 Annual Results; EDF, Press Release: Paris, France, 2020.

24. Innogy. Annual Report 2019; Innogy SE: Essen, Germany, 2020.

25. Anaya, K.L.; Pollitt, M.G. Options for allocating and releasing distribution system capacity: Deciding between interruptible connections and firm DG connections. Appl. Energy 2015, 144, 96-105. [CrossRef]

26. Pownall, T.; Soutar, I.; Mitchell, C. Re-Designing GB's Electricity Market Design: A Conceptual Framework Which Recognises the Value of Distributed Energy Resources. Energies 2021, 14, 1124. [CrossRef]

27. E.DSO; CEDEC; ENTSO-E; Euroelectric; GEODE. TSO-DSO Report. An Integrated Approach to Active System Management; E.DSO: Brussels, Belgium, 2019.

28. Council of European Energy Regulators. Incentives Schemes for Regulating, Distribution System Operators, Including for Innovation; A CEER Consultation Paper; CEER: Brussels, Belgium, 2018.

29. Abjdullah, S.; Wilner Jeanty, P. Willingness to pay for renewable energy: Evidence from a contigent valuation survey in Kenya. Renew. Sustain. Energy Rev. 2011, 15, 2974-2983. [CrossRef]

30. Du, P.; Zheng, L.-Q.; Bai-Chen, X.; Mahalingam, A. Barriers to the adoption of energy-saving technologies in the building sector: A survey study of Jing-jin-tang, China. Energy Policy 2014, 75, 206-216. [CrossRef]

31. Su, W.; Liu, M.; Zeng, S.; Štreimikienè, D.; Baležentis, T.; Ališauskaitė-Šeškienè, I. Valuating renewable microgeneration technologies in Lithuanian households: A study on willingness to pay. J. Clean. Prod. 2018, 191, 318-329. [CrossRef]

32. BNetzA. Flexibility in the Electricity System. Status Quo, Obstacles and Approaches for a Better Use of Flexibility; Discussion Paper; Bundesnetzagentur: Bonn, Germany, 2019.

33. Australian Energy Regulator. Final Decision: Demand Management Incentive Scheme and Innovation Allowance; AER: Melbourne, Australia, 2017.

34. Office of Gas and Electricity Markets. RIIO-ED2 Methodology Consultation: Overview; Ofgem: London, UK, 2020.

35. The Norwegian Water Resources and Energy Directorate. Proposed Changes to the Design of Network Tariffs for Low Voltage Grid Users in Norway; RME Rapport Nr. 2/2020, English Summary; Reguleringsmyndigheten for Energi-RME: Oslo, Norway, 2020.

36. International Renewable Energy Agency. Innovation Landscape Brief: Time-of-Use Tariffs; IRENA: Abu Dhabi, United Arab Emirates, 2019.

37. Van Langen, V. Tariff Setting Methodology for Electricity Distribution in The Netherlands. Case Study on the Dutch Yardstick and Capacity Tariffs; Presentation Made in Energy Community Vienna, Authority of Consumers \& Markets: Vienna, Austria, 2019.

38. Authority for Consumers \& Markets. Verkenning naar de Mogelijkheden van Flexibilisering van Nettarieven; D-Cision B.V. \& Ecorys B.V.: Zwolle, The Netherlands, 2019.

39. SA Power Networks. 2020-2025 Tariff Structure Statement Part A; SAPN: Adelaide, Australia, 2020.

40. Australian Energy Market Commission. Consultation Paper. Distributed Energy Resources Integration-Updating Regulatory Arrangements; AEMC: Sidney, Australia, 2020.

41. Australia Renewable Energy Agency. DEIP AccessEPricing Reform Package. Outcomes Report; Distributed Energy Integration Program; ARENA: Canberra, Australia, 2020.

42. Commission de Regulation de L'energie. Contrats D'électricité à Tarification Dynamique; CRE: Paris, France, 2020 .

43. Office of Gas and Electricity Markets. Electricity Network Access and Forward-Looking Charging Review: Open Letter on Our Shortlisted Policy Options; Ofgem: London, UK, 2020.

44. Energy Networks Association. Active Power Services Implementation Plan; Version 1.1; WS1A P3; ENA: London, UK, 2020.

45. Office of Gas and Electricity Markets. RIIO-ED2 Methodology Decision: Overview; Ofgem: London, UK, 2020.

46. Greve, T.; Teng, F.; Pollitt, M.G.; Strbac, G. A system operator's utility function for the frequency response market. Appl. Energy 2018, 231, 562-569. [CrossRef]

47. GOPACS, Grid Operators Platform for Congestion Solutions. Available online: https:/ / en.gopacs.eu/ (accessed on 28 May 2021).

48. Ministry of Economy, Trade and Industry. The First Meeting on the Platform for Distributed Energy Systems; METI: Tokyo, Japan, 2019.

49. The Norwegian Water Resources and Energy Directorate. Pilot and Demonstrations Projects. Available online: https://www.nve. no/reguleringsmyndigheten/bransje/bransjeoppgaver/pilot-og-demonstrasjonsprosjekter/ (accessed on 28 May 2021).

50. Enedis. Flexibilités Locales. Available online: https:/ / www.enedis.fr/co-construction-flexibilite-locale (accessed on 28 May 2021).

51. Energy Security Board. Moving to a Two-Sided Market; COAG Energy Council: Melbourne, Australia, 2020.

52. Energy Networks Australia. Open Networks Project. Position Paper; Energy Networks: Melbourne, Australia, 2020.

53. Australian Energy Market Commission. Wholesale Demand Response Mechanism, Rule Determination; AEMC: Sidney, Australia, 2020. 
54. The Norwegian Water Resources and Energy Directorate. Fra Brettet til det Smarte Nettet Ansvar for Driftskoordinering i Kraftsystemet; Reguleringsmyndigheten for Energi-RME: Oslo, Norway, 2020.

55. Office of Gas and Electricity Markets. RIIO-2 Sector Specific Methodology-Core Document; Decision; Ofgem: London, UK, 2019.

56. Office of Gas and Electricity Markets. Statutory Consultation on the Proposed Whole Electricity System Licence Condition [D7] [7A] for Electricity Distributors and Transmission Owners; Ofgem: London, UK, 2020.

57. Kristov, L.; De Martini, P.; Taft, J. Two Visions of a Transactive Electric System. IEEE Power Energy Mag. 2016, 14, 63-69. [CrossRef]

58. Australian Energy Market Operator. Electricity Rule Change Proposal. DER Minimum Technical Standards; AEMO: Sidney, Australia, 2020.

59. Catapult. A Strategy for a Modern Digitalised Energy System; Energy Data Taskforce Report; Energy Systems Catapult: Birmingham, UK, 2019.

60. Koerner, M.; Graham, P.; Spak, B.; Walton, F.; Kerin, R. Value of Distributed Energy Resources: Methodology Study; Final Report; CSIRO: Canberra, Australia, 2020.

61. Energy Networks Association. Common Evaluation Methodology and Tool; ENA: London, UK, 2020.

62. HM Treasury. The Green Book: Central Government Guidance on Appraisal and Evaluation; HM Treasury: London, UK, 2020. 